В. А. Краснобаєв, А. С. Янко, І. В. Філь

Полтавський національний технічний університет імені Юрія Кондратюка, Полтава, Україна

\title{
АНАЛІЗ МЕТОДІВ РЕАЛІЗАЦІЇ АРИФМЕТИЧНИХ ОПЕРАЦІЙ У КЛАСІ ЛИШКІВ
}

\begin{abstract}
У статті розглядаються особливості реалізації арифметичних операцій непозиційної системи числення у класі лишків. Реалізація арифметичних операцій у класі лишків виконуються незалежно і паралельно над однойменними розрядами (залишками), а структура операційного пристрою комп'ютерних засобів обробки даних представляється у вигляді незалежних обчислювальних трактів, кожен з яких функціонує за своєю основою ті класу лишків. Розглядаються та аналізуються методи реалізації модульних арифметичних операцій у класі лишків. Результати аналізу основних властивостей класів лишків дозволяють зробити висновок про те, що комп'ютерних засобів обробки даних, які функціонують у класі лишків, відносяться до швидкодіючих та надійних об'єктів. Зазначені особливості структури та принципів функціонування комп'ютерних засобів обробки даних у класі лишків сприяють розробці ефективних й оптимальних методів резервування, що не мають аналогів в позиційних системах числення.
\end{abstract}

Ключові слова: клас лишків, комп'ютерні засоби обробки даних, комп'ютерна системи, методи реалізації арифметичних операцій, непозиційна система числення, позиційна система числення.

\section{Вступ}

Постановка проблеми. Підвищення ефективності роботи комп'ютерної системи (КС), збільшення терміну експлуатації, розширення міжремонтних інтервалів, скорочення термінів виконання ремонтів, підвищення безвідмовності функціонування та підвищення продуктивності обробки інформації на сьогоднішній день $є$ актуальними завданнями в значній мірі залежить від принципів побудови і функціонування комп'ютерних засобів обробки даних (КЗОД).

У КЗОД дії проводяться над числами, представленими у вигляді спеціальних машинних кодів у прийнятій системі числення. Залежно від способу зображення чисел за допомогою цифр, існуючі системи числення умовно ділять на: позиційні, непозиційні та змішані системи.

Існує два основних принципи підвищення надійності КЗОД, які функціонують у позиційних системах числення: підвищення надійності окремих логічних елементів і схем (використання нової елементної бази) і введення різних типів (видів) надлишковості (застосування різних видів резервування, які впливають на надійність функціонування КЗОД). Оскільки надійність логічних елементів в основному визначається рівнем розвитку технології, то очевидно, що введення надмірності при використанні будь-якої елементної бази є найбільш ефективним шляхом підвищення надійності КЗОД.

Різноманіття умов функціонування КЗОД і жорсткість вимог (необхідність забезпечення високого ступеня точності обчислень, високої продуктивності та надійності функціонування КЗОД в реальному часі, висока швидкість передачі та обробки інформації, оперативна відновлюваність працездатного стану КЗОД після відмов і збоїв та інше), які пред'являються до режимів функціонування та експлуатації, не завжди дозволяють ефективно застосовувати різні види резервування.

Внаслідок цього одним $з$ ефективних практичних методів підвищення надійності КЗОД є структурне резервування, наприклад, на рівні дубльованої або тройованої мажоритарних структур обробки інформації. Однак застосування структурного резервування ускладнює структуру КЗОД, призводить до збільшення енергоспоживання, масогабаритних показників і погіршує інші важливі технічні характеристики, що в кінцевому підсумку підвищує вартість іï створення і експлуатації, а також обмежує сферу іiї застосування для обробки інформації в різних інформаційно-керуючих системах і для різних умов їх функціонування, що негативно впливає на технічні характеристики в цілому $[1,2]$.

Ця обставина обумовлює необхідність розробки і застосування принципово нових методів підвищення продуктивності і надійності КЗОД, заснованих на використанні нових принципів й ідей. Зокрема, методів обробки інформації, заснованих на нових системах числення. Проблема вибору систем числення для подання чисел у КЗОД має велике практичне значення. У разі їі вибору звичайно враховуються такі вимоги, як надійність подання чисел при використанні фізичних елементів, економічність (використання таких систем числення, в яких кількість елементів для подання чисел із деякого діапазону була б мінімальною).

Аналіз останніх досліджень і публікацій. Результати досліджень, що проводилися протягом останніх десятиліть, методів підвищення продуктивності та достовірності обчислень КЗОД, що в межах позиційних систем числення (ПСЧ) цього домогтися практично неможливо. Це обумовлено, у першу чергу, основним недоліком сучасних КЗОД, що функціонують у ПСЧ: наявність міжрозрядних зв'язків між операндами, що обробляються. Це впливає на архітектуру КЗОД і методи реалізації арифметичних операцій, ускладнює апаратуру та обмежує швидкодію виконання арифметичних операцій. У зв'язку з цим підвищення продуктивності КЗОД у ПСЧ здійснюється, перш за все, за рахунок підвищення тактової частоти, розвитку та застосування методів і засобів паралельної обробки даних.

Спираючись на фундаментальні поняття, положення і результати теорії чисел, була створена 
непозиційна система числення у класі лишків (КЛ), використання якої дозволило отримати цікаві результати в області реалізації арифметичних операцій. КЛ - система числення, в якій числа представляються у вигляді сукупності невід'ємних залишків по групі взаємно простих основ. У зв'язку з цим поданням виникла можливість виконання раціональних операцій без урахування розрядних зв'язків між цифрами числа.

Цей науковий напрям є розвитком, з одного боку, ідеї багатозалишкового кодування даних в позиційних системах числення i, з іншого, - кластерних систем обробки інформації [3-5].

Результати досліджень в області створення швидкодіючих КЗОД відомих авторів (Валаха М., Свободи А., Сабо Н., Акушського І. Я., Юдицького Д. І., Николайчука Я. М., Долгова О. І., Торгашова В. А., Амербаєва В. М., Shimbo A., Paulier P., Thornton M. A., Dreschler R., Miller D. M. та ін.) показали, що використання в якості системи числення непозиційної системи числення, а саме КЛ, може суттєво позитивно вирішити науково-прикладну задачу забезпечення надійної роботи КС без зниження продуктивності обробки інформації і з істотним зменшенням, у порівнянні з позиційною системою числення, кількості додатково необхідного обладнання.
Дана обставина дає можливість істотно підвищити надійність КЗОД, а також поліпшити деякі важливі техніко-економічні характеристики КС [6].

\section{Основна частина}

В позиційній системі числення виконання арифметичних операцій передбачає послідовну обробку розрядів операндів по правилам даної операції і не може бути закінчено до тих пір, поки не будуть послідовно визначені результати міжрозрядних операцій з врахуванням всіх зв'язків між розрядами.

Таким чином, ПСЧ, що використовуються в сучасних машинах, в яких представляється і оброблюється інформація, мають суттєвий недолік - наявність міжрозрядних зв'язків, які накладають свій відбиток на принципи реалізації арифметичних операцій, ускладнюють апаратуру і обмежують швидкодію. Тому природно, що здійснюється пошук можливостей застосування такої арифметики, в якій би порозрядні зв'язку були відсутні. У цьому плані звертає на себе увагу система числення у КЛ.

Реалізація арифметичних операцій у КЛ виконуються незалежно і паралельно над однойменними розрядами (залишками), а структура операційного пристрою КЗОД представляється у вигляді незалежних обчислювальних трактів, кожен з яких функціонує за своєю основою $m_{i}$ КЛ (рис. 1).

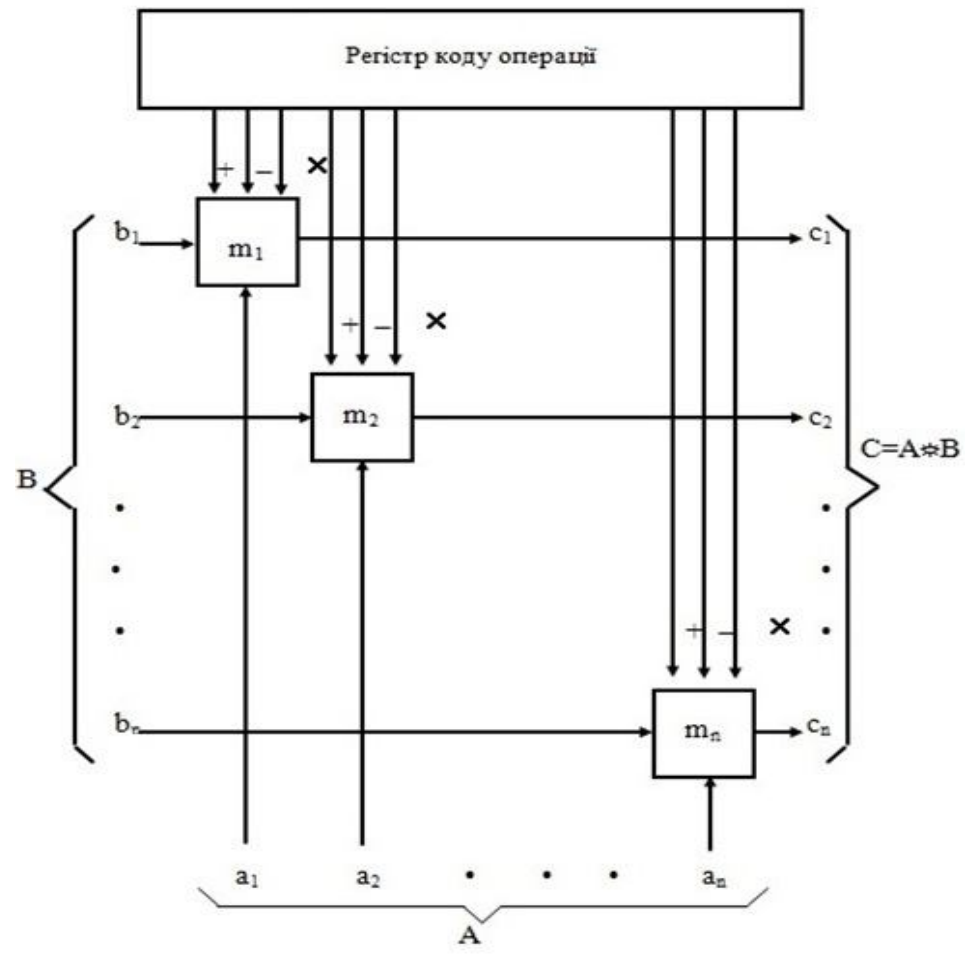

Рис. 1. Схема виконання арифметичних операцій у КЛ

Додавання, віднімання і множення в КЛ здійснюється по дуже простому алгоритму: ці операції модульні і здійснюються незалежно по кожному модулю КЛ в межах розрядної сітки $[0, \mathrm{M})$.

Позначивши узагальнену арифметичну операцію через символ же важко реалізувати алгоритм виконання арифметичних операцій у КЛ в загальному вигляді: нехай $\mathrm{A}=\left(\mathrm{a}_{1}, \ldots, \mathrm{a}_{\mathrm{n}}\right), \mathrm{B}=\left(\mathrm{b}_{1}, \ldots, \mathrm{b}_{\mathrm{n}}\right)$, тоді:

$\mathrm{C}=\mathrm{A}=\mathrm{B}=\left[\left(\mathrm{a}_{1}, \mathrm{~b}_{1}\right) \bmod \mathrm{m}_{1},\left(\mathrm{a}_{2}-\mathrm{b}_{2}\right) \bmod \mathrm{m}_{2}\right.$, $\left.\ldots,\left(a_{n}-b_{n}\right) \bmod m_{n}\right]$.

За рахунок властивості КЛ - незалежності залишків за прийнятою системою основ, відкриваються широкі можливості в побудові не тільки нової машинної арифметики, але й принципово нової схемної реалізації КЗОД, котра, в свою чергу помітно 
розширює застосування машинної арифметики [4]. Це дає можливість широкого вибору варіантів системотехнічних рішень при реалізації модульних арифметичних операцій, заснованих за допомогою наступних методів (принципів):

- суматорний метод (на базі малорозрядних двійкових суматорів);

- табличний метод (на основі використання таблиць ПЗП);

- метод кільцевого зсуву, заснований на використанні кільцевих регістрів зсуву (КРЗ).

При суматорному методі реалізації арифметичних операцій використовується $n$ (по числу основ КЛ) малорозрядних суматорів по відповідних модулях $m_{i}(i=\overline{1, n})$.

При побудові КЗОД, що функціонують у КЛ на базі малорозрядних суматорів (суматорний метод) кожен із розрядів числа обробляється незалежно, але час виконання всієї операції визначається часом необхідним для отримання результату по найбільшій основі КЛ.

Відмітимо основні недоліки суматорного методу:

- складність синтезу двійкових суматорів;

- значний час перетворення інформації, що визначається максимальною основою КЛ;

- неефективне використання двійкових елементів КЗОД в наслідок надлишковості представлення максимальних чисел.

Пошук шляхів одночасного підвищення продуктивності обробки інформації та надійності функціонування КЗОД привів до необхідності розробки табличного методу реалізації модульних операцій, заснованого на використанні таблиць ПЗП.

У загальному випадку табличний операційний пристрій КЗОД для реалізації арифметичних операцій (які реалізується в унітарній коді ) являє собою двохвходове ПЗП. Для кожного 3 входів кількість вхідних шин для $l$-байтової ( $8 l$ двійкових розрядів) КЗОД рівна $2^{8 l}$. При цьому загальна кількість логічних схем співпадання (збігу) “I” у вузлах ПЗП (яке в основному і визначає загальну кількість обладнання табличного операційного пристрою КЗОД) рівна $N_{l \text { псч }}=2^{8 l} \times 2^{8 l}=2^{16 l}$. Виходячи 3 формули, очевидно, що таблична реалізація цілочисельних модульних арифметичних операцій у ПСЧ доцільна лише для значення $l=1$. Дійсно, в цьому випадку $N_{1}=2^{16}$ $=65536$, що $\epsilon$ прийнятним за кількістю обладнання для сучасного розвитку елементної бази. Однак, як зазначалося вище, тенденція розвитку засобів обробки цифрової інформації спрямована на збільшення довжини розрядної сітки КЗОД.

Вже зараз пропонується до практичного використання КЗОД для $l=2$.

$\mathrm{y}$ цьому випадку $\mathrm{N}_{4 \Pi с ч}=2^{32} \times 2^{32}=2^{64}$ та $\mathrm{N}_{8 \Pi \text { пч }}=2^{64} \times 2^{64}=2^{128}$. Якщо врахувати, наприклад, $2^{32}=4294967296, \quad 2^{64}=18446744073709551616, \quad$ а $2^{128} \approx 3,4 \times 10^{38}$, то очевидно, що табличний метод реалізації арифметичних операцій в ПСЧ практично не застосовується.

Інші, позитивні результати, можна отримати, якщо розглянути КЗОД у КЛ. Дійсно, в загальному випадку, при реалізації алгоритмів модульної обро- бки інформації для табличного операційного пристрою КЗОД необхідна така кількість схем збігу:

$$
N_{l \text { КЛ }}=\sum_{i=1}^{n} m_{i}^{2},
$$

Тоді для КЗОД у КЛ з $l=4$ i $l=8$ відповідно маємо $N_{4 \kappa л}=2397$ та $N_{8 \kappa л}=13275$, що цілком прийнятно при реалізації арифметичних операцій додавання, віднімання та множення у КЛ, використовуючи сучасну елементну мікроелектронну базу (НВIC, ПЛМ або ПЛІС).

Переваги табличного методу реалізації арифметичних операцій КЗОД у КЛ:

- табличні схеми мають високу надійність, так як реалізуються у вигляді компактних ПЗП, в цьому випадку весь тракт операційного пристрою КЗОД будується за блоковим принципом, що покращує ремонтопридатність КЗОД (зменшується час відновлення);

- простота табличних схем і дешифраторів, що мають кількість виходів, відповідних основам $m_{i}$ КЛ;

- висока швидкодія - результат операції може бути отриманий в момент надходження вхідних операндів, тобто в один такт; час виконання арифметичних операцій у КЛ практично співпадає 3 тактовою частотою обчислювача, що принципово неможливо для позиційних обчислювальних машин при існуючій елементній базі.

Вищевикладене підтверджує важливість, доцільність та ефективність проведення практичних досліджень і розробок табличного методу реалізації модульних операцій у КЛ.

Малорозрядність залишків $a_{i}$ дає нам можливість реалізації арифметичних операцій у КЛ, або на базі малорозрядних двійкових суматорів (суматорний метод), або за допомогою табличного методу. При першому методі реалізації арифметичних операцій проявляється (хоча і в значно меншій ступені) той же недолік, що й у ПСЧ: наявність міжрозрядних зв'язків у межах даної основи $m_{i}$ КЛ. При табличному методі реалізації арифметичних операцій відсутні міжрозрядні зв'язки між обробляючими операндами взагалі, однак, для достатньо великої розрядної сітки КЗОД (для великих за величиною модулів КЛ) різко збільшується кількість обладнання операційних пристроїв. Важливо та актуально розглянути проміжний варіант реалізації арифметичних операцій у КЛ, заснований на застосуванні методу кільцевого зсуву шляхом використання кільцевих регістрів зсуву (КРЗ). У [7] сформований принцип реалізації арифметичних операцій на основі методу кільцевого зсуву, особливість котрого в тому, що результат арифметичної операції

$$
\left(a_{i} \pm \beta_{i}\right) \bmod m_{i}
$$

за довільним модулем КЛ, заданої сукупності $\left\{m_{j}\right\}, j=\overline{1, n}$, основ, визначається тільки за рахунок послідовно циклічних зсувів заданої цифрової структури. 
Перевага методу кільцевого зсуву в порівнянні 3 методами, заснованими на вживанні двійкових суматорів, полягає у відсутності міжрозрядних перенесень, що істотно підвищує достовірність реалізації модульних операцій. Проте час виконання модульних операцій порівняно великий, що знижує загальну ефективність вживання КЗОД у КЛ. Дана обставина й обумовлює необхідність розробки алгоритмів підвищення швидкодії виконання даних операцій у КЗОД [8].

Максимальної швидкодії виконання арифметичних операцій при використанні методу кільцевого зсуву можна досягти, використовуючи програмний метод реалізації модульних операцій. В цьому випадку, використовуючи керуючі матриці, в більшості варіантів результат операції $\left(a_{i} \pm \beta_{i}\right) \bmod m_{i}$ можна досягти за менше, ніж $k \beta_{i}$, число зсувів двійкових розрядів. Це обумовлено тим, що зсув вмісту КРЗ проводиться відповідно до даних керуючих матриць на число двійкових розрядів, кратне величині $\beta_{i}$, тобто на мінімально необхідне число двійкових розрядів. Здійсненність даної процедури обумовлена надмірністю вмісту розрядів КРЗ. Вміст керуючих матриць визначається для кожної операції (додавання, віднімання і т.п.) і для кожної основи $m_{i}$ КЛ індивідуально. Вузлу керуючої матриці присвоюється значення (3 урахуванням напряму зсуву), рівне кількості необхідних зсувів вмісту двійкових розрядів КРЗ [9].

\section{Висновки}

У даний час неможливо уявити собі автоматичну систему без того, щоб іiї центральну частина не складали обчислювальні машини, що виконують функції обробки інформації та управління. У КЗОД дії проводяться над числами, представленими у вигляді спеціальних машинних кодів у прийнятій системі числення. Залежно від способу зображення чисел, за допомогою цифр, існуючі СЧ умовно ділять на: позиційні та непозиційної системи.

Результати, що проводилися протягом останніх років різними групами дослідників щодо пошуку шляхів підвищення продуктивності КЗОД, методів організації ефективної системи виявлення та виправлення помилок і побудови високонадійних обчислювальних комплексів утвердилися в думці, що в межах ПСЧ не можна очікувати скільки-небудь задовільного результату без істотного збільшення робочих частот елементів й ускладнення апаратурною частини КЗОД.
Слід зазначити, що ПСЧ, в яких представляється й обробляється інформація в сучасних КЗОД, мають істотний недолік - наявність міжрозрядних зв'язків, які накладають свій відбиток на способи реалізації арифметичних операцій, ускладнюють апаратуру і обмежують швидкодію КЗОД.

Все це стало поштовхом до пошуку нових систем числення і нових методів організації КЗОД. Дослідження проведені в НСЧ, названій КЛ призвели до створення досить своєрідної машинної арифметики. У КЛ числа представляються своїми залишками від ділення на обрану систему основ, і всі раціональні операції можуть виконуватися паралельно над цифрами кожного розряду окремо. Основні властивості КЛ (незалежність залишків, рівноправність залишків, малорозрядність залишків) дозволяють усунути недоліки ПСЧ. Спільне використання першої і другої властивостей (незалежності й рівноправності залишків) обумовлює наявність у КЗОД одночасно трьох основних видів резервування: структурного, інформаційного та функціонального. А така властивість КЛ, як малорозрядність залишків дає можливість широкого вибору реалізації арифметичних операцій, заснованих на наступних методах:

- суматорному методі (на базі малорозрядних двійкових суматорів);

- табличному методі (на основі використання таблиць ПЗП);

- методі кільцевого зсуву, що заснований на використанні кільцевих регістрів зсуву.

Проаналізовано особливості методів технічної реалізації арифметичних операцій у КЛ. Аналіз відомих методів показав, що найбільш оптимальним 3 точки зору максимальної швидкодії виконання арифметичних операцій і забезпечення заданого рівня надійності функціонування КЗОД є табличний метод реалізації модульних операцій. Показано, що задачі, пов'язані з необхідністю використання табличної арифметики доцільно і ефективно вирішувати тільки у КЛ.

Результати аналізу основних властивостей КЛ дозволяють зробити висновок про те, що КЗОД, що функціонують у КЛ, відносяться до швидкодіючих та надійних об'єктів. Зазначені особливості структури та принципів функціонування КЗОД у КЛ сприяють розробці ефективних й оптимальних методів резервування, що не мають аналогів в ПСЧ.

\section{СПИСОК ЛІТЕРАТУРИ}

1. Дадаев Ю. Г. Теория арифметических кодов / Ю. Г. Дадаев. - М. : Радио и связь, 1981. - 272 с.

2. Акушский И. Я. Основы машинной арифметики комплексных чисел / И. Я. Акушский, В. М. Амербаев, И. Т. Пак. Алма-Ата : Наука, 1970. - 248 с.

3. Амербаев, В. М. Теоретические основы машинной арифметики / В.М. Амербаеав. - Алма-Ата, Наука, 1976. - 324 с.

4. Акушский И. Я. Машинная арифметика в остаточных классах / И. Я. Акушский, Д. И. Юдицкий. - М. : Советское радио, 1968. - $440 \mathrm{c}$.

5. Koshman S. A. Method of bit-by-bit tabular realization of arithmetic operations in the system of residual classes / S. A. Koshman, V. I. Barsov, V. A. Krasnobayev, K. V. Yaskova, N. S. Derenko // Радіоелектронні і комп'ютерні системи. -2009 . - № 5 (39). - C. 44-48.

6. Gbolagade K. A. An O(n) Residue Number System to Mixed Radix Conversion technique / K. A. Gbolagade, S. D. Cotofana // IEEE International Symposium on Circuits and Systems (24-27 May, 2009). - New York : IEEE, 2009. - P. 521-524.

7. Krasnobayev V. A Method for arithmetic comparison of data represented in a residue number system / V. Krasnobayev, A. Yanko and S. Koshman // Cybernetics and Systems Analysis. - vol. 52, Issue 1. - 2016. - pp. 145-150.

8. Krasnobayev V. A method for operational diagnosis of data represented in a residue number system / V. Krasnobayev and 
S. Koshman // Cybernetics and Systems Analysis. - vol. 54, Issue 2. - 2018. - pp. 336-344.

9. Krasnobayev V. Algorithms of data processing in the residual classes system / V. Krasnobayev, A. Yanko and S. Koshman // 4th International Scientific-Practical Conference Problems of Infocommunications. Science and Technology (PIC S\&T) .Kharkiv. - 2017. - pp. 117-121.

\title{
REFERENCES
}

1. Dadaev Yu. G. Theory of arithmetic codes / Yu. G. Dadaev. - M.: Radio and communication, 1981. - 272 pages.

2. Akushsky I. Ya. Fundamentals of machine arithmetic of complex numbers / I. Ya. Akushsky, V. M. Amerbaev, I. T. Pak. Alma-Ata: Science, 1970. - 248 pages.

3. Amerbaev V.M. Theoretical Foundations of Machine Arithmetic / V.M. Amerbaeav. - Alma-Ata, Science, 1976. 324 pages.

4. Akushskii I. Ya. Machine arithmetic in residual classes / I. Ya. Akushskii, D. I. Yuditskii. - M.: Soviet Radio, 1968. - 440 pages.

5. Koshman S. A. Method of bit-by-bit tabular realization of arithmetic operations in the system of residual classes / S. A. Koshman, V. I. Barsov, V. A. Krasnobayev, K. V. Yaskova, N. S. Derenko // Радіоелектронні і комп'ютерні системи. - 2009. - № 5 (39). - С. 44-48.

6. Gbolagade K. A. An O(n) Residue Number System to Mixed Radix Conversion technique / K. A. Gbolagade, S. D. Cotofana // IEEE International Symposium on Circuits and Systems (24-27 May, 2009). - New York : IEEE, 2009. - P. $521-524$.

7. Krasnobayev V. A Method for arithmetic comparison of data represented in a residue number system / V. Krasnobayev, A. Yanko and S. Koshman // Cybernetics and Systems Analysis. - vol. 52, Issue 1. - 2016. - pp. 145-150.

8. Krasnobayev V. A method for operational diagnosis of data represented in a residue number system / V. Krasnobayev and S. Koshman // Cybernetics and Systems Analysis. - vol. 54, Issue 2. - 2018. - pp. 336-344.

9. Krasnobayev V. Algorithms of data processing in the residual classes system / V. Krasnobayev, A. Yanko and S. Koshman // 4th International Scientific-Practical Conference Problems of Infocommunications. Science and Technology (PIC S\&T) .Kharkiv. - 2017. - pp. 117-121.

Рецензент: д-р техн. наук, проф. С. Г. Рассомахін, Харківський національний університет імені В.Н. Каразіна, Харків Received (Надійшла) Accepted for publication (Прийнята до друку)

\section{Анализ методов реализации арифметических операций в классе вычетов}

\author{
В. А. Краснобаєв, А. С. Янко, І. В. Філь
}

В статье рассматриваются особенности реализации арифметических операций непозиционной системы счисления в классе вычетов. Реализация арифметических операций в классе вычетов выполняются независимо и параллельно над одноименными разрядами (остатками), а структура операционного устройства компьютерных средств обработки данных представляется в виде независимых вычислительных трактов, каждый из которых работает по своему основанию $m_{i}$ класса вычетов. Рассматриваются и анализируются методы реализации модульных арифметических операций в классе вычетов. Результаты анализа основополагающих свойств классов вычетов позволяют сделать вывод про то, что компьютерные способы обработки данных, которые функционируют в классе вычетов, относятся к быстродействующим и надежным объектам. Определенные особенности структуры и принципа действия компьютерных средств обработки данных в классе вычетов способствуют разработке более эффективных и оптимальных методов резервирования, которые не имеют аналогов в позиционных системах счисления.

Ключевы е слов а: класс вычетов, компьютерные средства обработки данных, компьютерная системы, методы реализации арифметических операций, непозиционной система счисления, позиционная система счисления.

\section{Analysis of methods for the implementation of arithmetic operations in the residual classes}

V. Krasnobayev, A. Yanko, I. Fil

The article discusses the features of the implementation of the arithmetic operations of nonpositional number systems in the residual classes. It is possible to increase the productivity of the computer system and the reliability of processing integer data based on the use of new machine arithmetic. In the positional numeral system, the execution of an arithmetic operation involves the sequential processing of the digits of operands according to the rules determined by the content of the operation, and cannot be completed until the values of all intermediate results are sequentially determined taking into account all the connections between the digits. Thus, positional numeral system, in which information is presented and processed in modern computers, have a significant drawback - the presence of inter-bit relations, which impose its imprint on the methods of implementing arithmetic operations, complicate the equipment and limit the speed. Therefore, it is natural to look for possibilities of using such arithmetic, in which there would be no queuing connections. In this regard, the system of calculus in the residual classes draws attention to itself. The implementation of arithmetic operations in the residual classes is performed independently and in parallel over the like digits (residues), and the structure of the operating unit of computer data processing facilities is represented as independent computational paths, each of which operates on its base mi of the residual classes. Adding, subtracting, and multiplying the residual classes is carried out using a very simple algorithm: these operations are modular and are implemented independently for each module of the residual classes within the boundary grid [0, M]. Methods of implementing modular arithmetic operations in the residual classes are considered and analyzed. There are three basic principles for the implementation of modular arithmetic operations in the residual classes, based on the following methods: an aggregation method (based on a low-level binary adder); tabular method; the method of a ring-shift, based on the use of ring shift registers.

Keywords: residual classes, computer data processing facilities, computer systems, methods for implementing arithmetic operations, non-positional number system, positional number system. 